\title{
Characterization of Variant Strain of Newcastle Disease Virus in Egypt
}

\author{
A. S. Abdel-Moneim ${ }^{* *}$, Azza A. El-Sawah ${ }^{2}$, M. A. Kandil ${ }^{3}$ \\ ${ }^{1}$ Department of Virology, ${ }^{2}$ Department of Poultry and Rabbit diseases, ${ }^{3}$ Department of \\ Biochemistry, Faculty of Veterinary Medicine, Beni-Suef University, Beni-Suef 62511, Egypt.
}

\begin{abstract}
During 2005, velogenic Newcastle disease virus (NDV) caused a major outbreak among commercial broiler chicken in Egypt. The outbreak raised concerns regarding the protective immunity of commercially available vaccines for prevention and control of this virus in poultry. The virus was isolated from broiler farm suffered from more than $95 \%$ mortalities. The isolate was confirmed not to be avian influenza virus (AIV) by rapid chromatographic strip test, and characterized as NDV using reverse transcription-polymerase chain reaction (RT-PCR) which amplified a portion of the fusion gene of NDV and haemagglutination inhibition (HI) test. This isolate confirmed to be velogenic viscerotropic NDV by mean death time (MDT) test and pathogenicity to 7-week old chickens. We tried to determine whether the existing commercial live NDV La Sota vaccine could provide protection against the isolated virus or not. Birds received a single dose of live La Sota type vaccine at 3 weeks of age and were challenged 2 weeks postvaccination with a lethal dose of NDV. Results indicated that the live vaccine did not protect against morbidity but reduced mortality in comparison to controls. All unvaccinated control chickens challenged with NDV died within 5 days post-challenge (pc). Protection from disease did not correlate with the presence of antibody titers (determined by $\mathrm{HI}$ ) at day of challenge. These results underscore the need to develop new NDV vaccines and vaccine strategies for use during outbreak situations to protect birds from both disease and infection and to reduce virus shedding.
\end{abstract}

Newcastle disease virus is responsible for one of the most devastating viral diseases of poultry and has substantial economic impact in the poultry industry. NDV is the only member of the genus Avulavirus, family Paramyxoviridae, subfamily Paramyxovirinae, in the order Mononegavirales and is designated avian paramyxovirus-1 (APMV-1) (Mayo, 2002). The NDV genome consists of six transcriptional units that encode the nucleocapsid protein (NP), phosphoprotein $(\mathrm{P})$, matrix protein $(\mathrm{M})$, fusion (F) protein, hemagglutinin protein $(\mathrm{HN})$, and the polymerase protein (L). Two additional proteins, $\mathrm{V}$ and $\mathrm{W}$, are expressed by mRNAs, which are derived from the $\mathrm{P}$ gene via RNA editing (Samson et al., 1991; Steward et al., 1993,1995). Isolates of NDV have been historically categorized into three pathotypes (Alexander, 2003). Lentogenic NDV isolates do not usually cause disease in adult birds, and utilized extensively as live-virus vaccines, mesogenic

\footnotetext{
* Corresponding author. Tel.: +20 125705482; fax: +20822327982 .

E-mail address: a_s_abdel_moneim@yahoo.com (A.S. Abdel-Moneim).
}

NDV isolates that cause respiratory disease, but are not usually fatal (Hanson and Brandly, 1955), and velogenic viscerotropic or neurotropic NDV isolates with high virulence forms (Alexander, 2003). Although NDV has only one serotype, there are 10 genotypes of NDV isolates based on differences on fusion protein gene (Lomniczi et al., 1998; Herczeg et al., 1999; Tsaia, et al., 2004). The primary molecular determinants for NDV pathogenicity are the fusion protein cleavage site amino acid sequence (Nagai et al., 1976; Glickman et al.,1988) and the ability of specific cellular proteases to cleave the fusion proteins of different pathotypes (Gotoh et al., 1992 ; Ogasawara et al., 1992). The presence of dibasic amino acids in the fusion protein sequence allows for systemic spread of velogenic NDV, whereas replication of lentogenic NDV is limited to mucosal surfaces of the host (Ogasawara et al., 1992).

The main objective of the present study was to identify the causative agent of the outbreak and investigate whether the NDV isolated strain possesses such antigenic changes that enable the 
strain overcoming vaccination barrier afforded by the commonly used La Sota vaccine.

\section{Material and Methods}

Embryonated chicken eggs (ECE). Specificpathogen-free (SPF) ECE obtained from Nile SPF (Koom Oshiem, Fayoum, Egypt) were used for isolation of the field isolate, titration of the seed stocks of NDV local isolate and vaccine strain, as well as pathogenicity test in ECE.

Chickens. Commercial 1-day-old Hyline chickens (El-Waddi Co, Egypt) were reared under strict hygienic conditions in separate rooms and used in both pathogenicity and protection studies.

Virus isolation in SPF ECE. NDV local isolate was isolated from 28-day-old broiler chickens suffering from both respiratory and renal distresses from Fayoum Governorate in 2005. Tracheal and proventicular scraping suspensions were pooled, centrifuged at $500 \mathrm{xg}$ for $10 \mathrm{~min}$. Antibiotic mixture $(1000 \mu \mathrm{g}$ penicillin and 1000 $\mathrm{mg}$ streptomycin $/ \mathrm{ml}$ ) was added to the supernatant clear fluid. The supernatant fluid was inoculated into chorioallantoic sac of 10day-old SPF ECE. Allantoic fluid was harvested after $72 \mathrm{~h}$ and re-passed for another egg set.

Virus titration. NDV local isolate and La Sota vaccine (Intervet International, Boxmeer, The Netherlands) were titrated as described by (Villegas and Purchase 1989). Virus titers were expressed as $50 \%$ embryo infectious doses $\left(\mathrm{EID}_{50}\right)$ according to (Reed and Meunch, 1938).

Avian influenza virus antigen detection. The allantoic fluid of the second passage was screened for AIV using rapid chromatographic strip test (Animal Genetic Inc. Korea) according to manufacturer instructions.

Haemagglutination inhibition test. NDV specific antibodies were titerated by HI assay according to (Beard, 1989). The test was conducted in round bottomed microtiter plates (Dynatech Lab., Alexandria, Virginia). Serial two fold dilutions of serum were prepared in phosphate buffered saline (PBS). Total volume of diluted serum was $25 \mu \mathrm{l}$ per well, then an equal volume of predetermined 4HA units of NDV was dispensed to each well. Incubation was conducted at $37^{\circ} \mathrm{C}$ for $1 \mathrm{~h}$ in a humidified chamber. Fifty microliters of $1 \%$ RBC was dispensed to each well. The plates were left at room temperature until positive serum well exhibit tight well circumscribed button of unagglutinated sedimented cells. Result of each sample was numerically reported as $\log _{2}$ of the highest dilution of serum at which there was complete inhibition of agglutination.

Reverse transcriptase polymerase chain reaction (RT-PCR). RNA from the local NDV isolate was extracted from infectious allantoic fluid using QIAamp viral RNA mini kit (Qiagen, Hilden, Germany) according to manufacturer instructions. The RNA elute was subjected to reverse transcription (RT) with Reverse-iTTM One-Step RT-PCR Kit (ABgene, Epsom, Surrey, United Kingdom) using NDV F-gene specific primers originally described by (Collins et al., 1993) (+)5'-TACACCTCATCC-CAGACAGG$3 '$ and (-) 5'-AGTCGGAGGATGTTGGCAGC3'. Briefly, total RNA elute was incubated at $47^{\circ} \mathrm{C}$ for 30 minutes followed by an additional incubation at $94^{\circ} \mathrm{C}$ for 4 minutes. The reaction was subsequently run for 30 cycles at $94^{\circ} \mathrm{C}$ for 30 seconds, $55^{\circ} \mathrm{C}$ for 15 seconds, and $72^{\circ} \mathrm{C}$ for 20 seconds, followed by an additional elongation at $72^{\circ} \mathrm{C}$ for 7 minutes. Reaction product was visualized by ethidium bromide staining under UV transillumination after electrophoresis on $1 \%$ agarose gel.

\section{Pathotyping of the NDV isolate.}

Mean death time (MDT) (Alexander, 1989). Fresh infective AF was diluted in sterile saline solution in ten fold dilution from $10^{6}$ to $10^{10}$. For each dilution $0.1 \mathrm{ml}$ of $\mathrm{AF}$ was inoculated into the allantoic cavity of five 10 days old embryonated chickens eggs and incubated at $37^{\circ} \mathrm{C}$. Remaining virus dilutions were retained at $4^{\circ} \mathrm{C}$ and inoculated into another five embryonated eggs with $0.1 \mathrm{ml}$ of each dilution $8 \mathrm{~h}$ later. Embryos were incubated at $37^{\circ} \mathrm{C}$ and examined twice daily for 7 days for their viability. Minimum lethal dose is the highest dilution of virus where all the embryos were dead. MDT is the mean time in hours for the minimum lethal dose to kill all the embryos.

Intravenous pathogenicity index to 7-week old chickens (Alexander, 1989). Fifteen 7-week old chickens were infected with NDV local isolate $0.1 \mathrm{ml}$ of $1: 10$ dilution of allantoic fluid by intravenous route. Birds were examined daily for 10 days and each bird is scored 0 if normal, 1 if sick, 2 if paralyzed and 3 if dead. IVPI value is the mean score per bird per observation.

Vaccination trial. Two groups (A, B) of one-old chickens were used to evaluate the protection provided by La Sota vaccine 


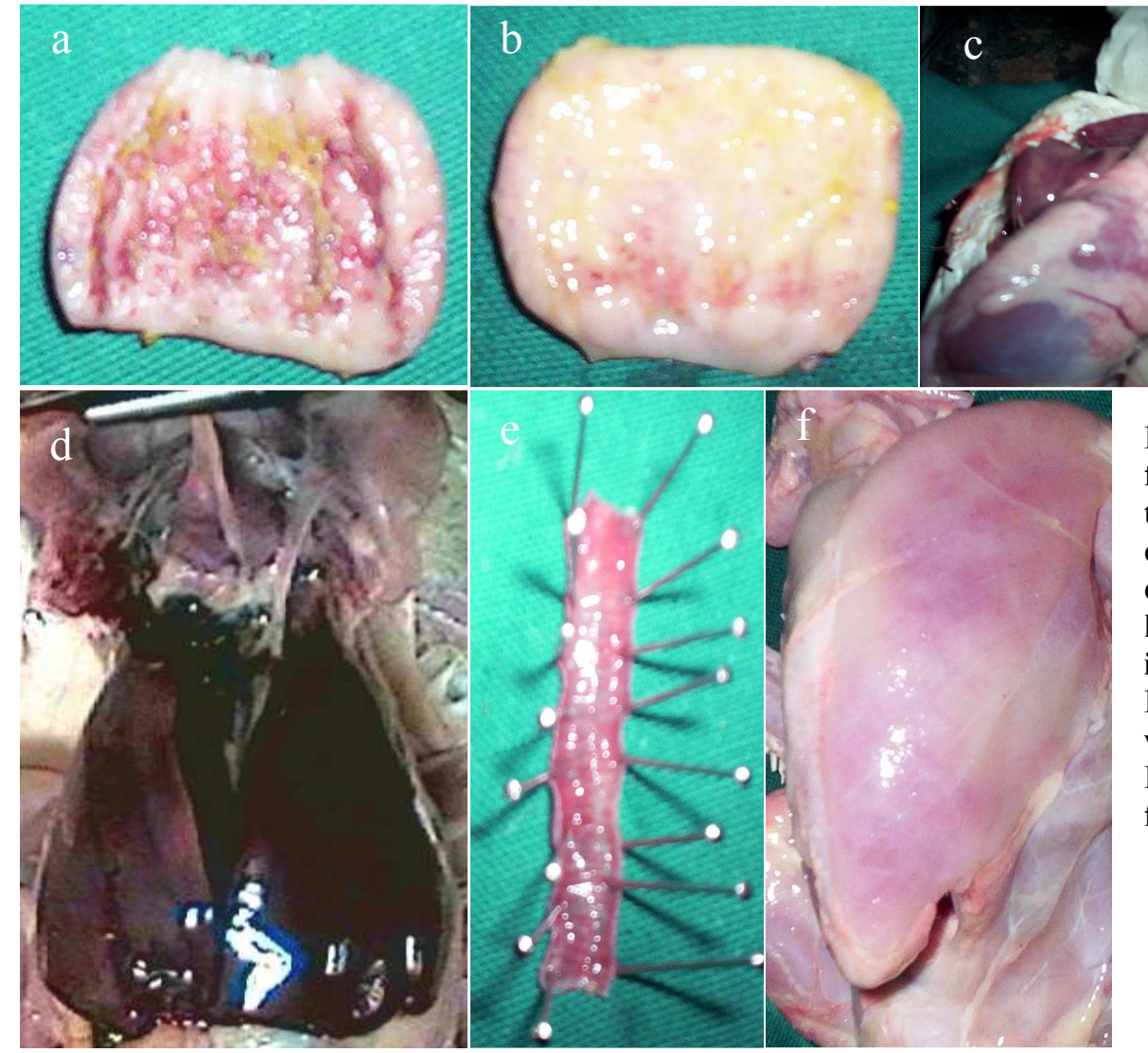

Fig.(1): Postmortem finding of NDV infected flock a., b. Proventriculi with various degree of haemorrhages. c. Congested internal viscera. d. Highly congested liver with hepatomegaly. e. Haemorrhagic trachea. f. Febrile carcass.

against challenge with NDV local isolate. HI antibody titers were measured at one day old chickens to determine the due time of vaccination (3-week of age). Birds in group A were vaccinated by eye drop La Sota vaccine $\left(10^{6.0}\right.$ EID $\left._{50}\right)$ according to manufacture instructions while that of group B were kept as control unvacinated. Two weeks post vaccination; chickens in group $\mathrm{A}$ and $\mathrm{B}$ were challenged by eye drop with $10^{5.9} \mathrm{EID}_{50}$ per bird of NDV local isolate (Kapczynski and King 2005). Clinical signs and mortalities were recorded.

\section{Results}

Clinical history. Newcastle disease was diagnosed during July 2005 in Fayoum Governorate, Egypt. The outbreak occurred in commercial broiler farm with flock density of 8000. The first signs were sever depression, green diarrhea, paresis and death two or three days after the onset of the disease. Other signs included sever conjunctivitis, facial swelling, birds standing dull with drooping wings. Within a period of 17-20 days after the appearance of the disease, the mortality increased progressively and by the end of such period 250 birds were the only survivors. Postmortem examination of dead birds showed generalized congestion in all organs with highly injected liver and splenomegaly (Fig.1c,d), haemrrhagic tracheitis (Fig.1e) and moderate (Fig.1b) to sever haemrrhages (Fig.1a) on the proventricular gland tips were also observed. The carcasses were febrile with congested muscles (Fig.1f). Emergency vaccination using NDV La Sota failed to stop or even reduce deaths.

Virus identification. The virus was haemagglutinating virus. AIV detection was confirmed to be negative by performing AIV antigen detection in replicate manner. The isolate was serologically identified as NDV by HI test using NDV polyclonal chicken serum.

Virus characterization. RT-PCR was performed on the allantoic fluid of the field isolate. Agarose gel electrophoresis of the RT-PCR product revealed a single band within the expected size; 305 bp (Fig.2) thus confirming that the virus is Newcastle disease virus.

Pathogenicity indices. The mean death time into chicken embryos was $60 \mathrm{~h}$. while inoculation of the virus in 7-week old chicken resulted in death of all inoculated birds indicated that this virus is extremely virulent for chickens with 2-3 IVPI. 
Table.1 Results of protection afforded by La Sota strain against challenge with NDV field isolate.

\begin{tabular}{|c|c|c|c|c|c|c|}
\hline \multirow{2}{*}{ Group $^{A}$} & \multirow{2}{*}{ Number } & \multirow{2}{*}{ Vaccination $^{\mathrm{B}}$} & \multirow{2}{*}{ Challenge $^{\mathrm{C}}$} & Prechallenge HI titers & \multicolumn{2}{|c|}{ Number of birds } \\
\hline & & & & Range $^{\mathrm{E}}$ & Sick & Dead \\
\hline $\mathrm{A}$ & 20 & + & + & $8-11$ & $16 / 20$ & $4 / 20$ \\
\hline $\mathrm{B}$ & 20 & + & - & $8-11$ & $0 / 20$ & $0 / 20$ \\
\hline $\mathrm{C}$ & 5 & - & + & 0 & $5 / 5$ & $5 / 5$ \\
\hline 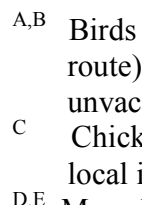 & $\begin{array}{l}\text { in groups } \\
\text { according } \\
\text { inated. } \\
\text { ens in grou } \\
\text { solate, two we }\end{array}$ & $\begin{array}{l}\text { A and } B \text { were } \\
\text { to manufacture } \\
A \text { and } B \text { wer } \\
\text { eks post vaccination }\end{array}$ & $\begin{array}{l}\text { vaccinated at } 3 \\
\text { instructions wh } \\
\text { e challenged by }\end{array}$ & $\begin{array}{l}\text { weeks of age by } \mathrm{La} \text { S } \\
\text { ile that of group B } \\
\text { eye drop with } 10^{5.9} \text { EII }\end{array}$ & $\begin{array}{l}\text { ta vaccin } \\
\text { ere kept } \\
50 \text { per bi }\end{array}$ & $\begin{array}{l}\text { eye drop } \\
\text { of NDV }\end{array}$ \\
\hline
\end{tabular}

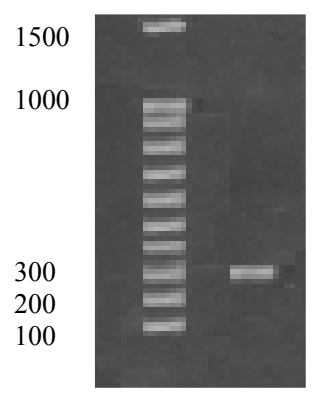

Fig.(2): Agarose gel electrophoresis a. Lane contained DNA molecular weight markers and b. PCR product of NDV isolate.

Protection test. The results obtained from the experiment to assess the ability of La Sota live vaccine to protect chickens against challenge with the NDV filed isolate are shown in Table 1. Although high $\mathrm{HI}$ immune response was obtained prior to challenge, unsatisfactory protection level was obtained. Results showed that the vaccine strain La Sota reduced overall clinical protection to $20 \%$ when challenged with Egyptian isolate, although it protected 16 out of the 20 chicks challenged with isolate against mortality but did not protect against clinical disease in $80 \%$ of vaccinated bids. None of the control chicks were protected after challenge. Clinical signs include diarrhoea, nasal discharge and birds standing dull with drooped wings. Postmortem examination of dead birds revealed generalized congestion in all parenchymatous organs and haemorrhages on the proventricular gland tips.

\section{Discussion}

In this study, isolation of an apparently new variant of Newcastle disease virus from broiler flock which experienced drastic mortality pattern in spite of being vaccinated by commonly used NDV vaccine. Preliminary haemagglutination inhibition and further RT-PCR tests as well as negative AIV antigen detection test revealed that the isolated strain is Newcastle disease virus. It has been demonstrated that the pathogenicity of Newcastle disease virus for chickens is dependent on the ability of the host non-trypsinlike proteases to cleave the precursor fusion protein $\mathrm{F} 0$ to $\mathrm{F} 1$ and $\mathrm{F} 2$; in some cases a similar mechanism is also required for haemagglutininneuraminidase protein (Rott and Klenk, 1988). Pathogenicity test to 7-week old chickens reproduce similar disease with $100 \%$ mortality rate. Diarrhoea, paresis and sever respiratory signs were detected in most birds.

It was known that ND viruses exist as a single serotype based on the neutralizing test and crossprotective analysis (Alexander, 1997) but 10 genotypes of NDV isolates based on differences on fusion protein gene are existed (Lomniczi et al., 1998; Herczeg et al., 1999; Tsaia et al., 2004). In view of recent outbreaks of ND in vaccinated chicken flocks of Egypt, we conducted a laboratory investigation to determine whether there was evidence of crossprotection between vaccine strain La Sota and field strain. It is well known that NDV antibody response is essential for clinical protection against challenge with virulent NDV (Reynolds and Maraqa, 2000) but this was not the case in our study. Although very high prechallenge HI antibody titers were obtained, unsatisfactory protection was afforded. Results revealed that La Sota-vaccinated chickens were only partially protected against challenge with recent isolate. 
Indeed it was an antigenic variant that escapes the protective immune response of the La Sota vaccine strain. In the last decades it has been reported many NDV outbreaks in vaccinated flocks (Yang et al., 1997,1999). Although antigenic differences detected between virulent viruses and vaccine strains are insufficient to result in failure of vaccination (Alexander et al., 1997), it does not seem reasonable to suspect that all cases are due to technical errors in vaccination performance or bad quality of the used vaccine. It is apt assumed that the disease caused by a pathogenic NDV strain having certain antigenic peculiarities helping to overcome vaccination barrier (Panshin et al., 2002).

Evolution of NDV, may be related to the accumulation of point mutations that induce amino acid substitution in the neutralizing epitopes, the cysteine residues, and N-linked glycosylation sites of the $\mathrm{F}$ protein (Chambers, et al., 1986; Toyoda et al., 1989; Yusoff et al., 1989). Immune pressure of the host may contribute to the difference in evolutionary rates as selective immune pressure of the host enhanced the evolutionary process of NDV (Yu et al., 2001).

In Egypt a strict vaccination program against ND has been performed for decades. These results suggested that selective immune pressure of the host enhanced the evolutionary process of NDV. Although, genetic analysis proves valuable tool in tracking the spread and origin of NDV in countries. However, neither the highly virulent and moderately virulent NDV strains nor the low-virulent and avirulent NDV strains can be distinguished by the cleavage site motifs (Yu et al., 2001). In addition, the phylogenetic relationship among NDV strains does not correlate well with cleavage site sequences and virulence ( $\mathrm{Yu}$ et al., 2001). This indicated that the virulence of NDV strains can be qualified rather than quantified by the analysis of cleavage site motifs and that pathogenicity tests such as MDT, ICPI and IVPI cannot be replaced by analysis of the cleavage site to precisely characterize virulence and pathogenicity of NDV strains.

This experiment demonstrated that La Sota vaccine was not full efficacious. This is supported by the evidence from the field in which very full vaccination program used was apparently insufficient to protect against challenge with this particular strain of the virus. The results presented here emphasize the importance of maintaining continued surveillance of vaccination procedures.

The continued outbreaks of velogenic NDV in domestic poultry worldwide emphasize the importance for continued research on vaccine efficacy against newly isolated strains. Studies on comparison of antigenic structure of the pathogenic NDV viruses isolated from different outbreaks with that of the viruses used for the vaccination are of crucial importance to determine the key question concerning the estimation of the possible risk to overcome the vaccination barrier.

\section{Acknowledgments}

The authors thank Prof. Magdy Fathy ElKady, Department of poultry and rabbit diseases, Faculty of Veterinary Medicine, Beni-Suef University, Egypt, for providing AIV chromatographic strip and for his kind scientific support.

\section{References}

Alexander, D. J. (1989): Newcastle disease. In A Laboratory Manual for the Isolation and Identification of Avian Pathogens, pp. 114-120. Edited by American Association of Avian Pathologists. Iowa: Kendall/Hunt Publishing Company.

Alexander, D. J. (1997): Newcastle disease and avian paramyxovirus infections, p. 541-569. In B. W. Calnek, H. J. Barnes, C. W. Beard, and L. R. McDougald (ed.), Diseases of poultry, $10^{\text {th }}$ ed. Iowa State University Press, Ames, Iowa.

Alexander, D. J. (2003): Newcastle disease, In Y.M. Saif, H.J. Barnes,A.M. Fadly,J.R. Glisson,L.R. McDougald,D.E. Swayne (ed.), Disease of poultry. 11th ed. Iowa State University Press, Ames, Iowa. pp. 64-87.

Alexander, D. J.; Manvell, R.J.; Lowing, J.P.; Frost, K.M.; Collins, M. S.; Russell, P.H. and Smith J.E. (1997):Antigenic diversity and similarities detected in avian paramyxovirus type 1 (Newcastle disease virus) isolates using monoclonal antibodies . Avian Pathol., 26:339-418.

Beard, C. W. (1989): Serological procedures: In A Laboratory Manual for the Isolation and Identification of Avian Pathogens, Edited by American Association of Avian Pathologists. Iowa: Kendall/Hunt Publishing Company. pp. 192-200.

Chambers, P.; Millar, N. S. and Emmerson, P. T. (1986): Nucleotide sequence of the gene encoding the fusion glycoprotein of Newcastle disease virus. J. Gen. Virol., 67:2685-2694

Collins, M. S.; Bashiruddin, J. B. and Alexander, D. J. (1993): Deduced amino acid sequences at the fusion protein cleavage site of Newcastle disease viruses showing variation in antigenicity and pathogenicity. Arch. Virol., 128: 363-370.

Glickman, R. L.; Syddall, R. J.; Iorio, R. M.; Sheehan, J. P. and Bratt, M. A. (1988): Quantitative basic residue requirements in the cleavage-activation site of the fusion glycoprotein as a determinant of virulence for Newcastle disease virus. J. Virol., 62: 354-356.

Gotoh, B.; Ohnishi, Y.; Inocencio, N. M.; Esaki, E.; Nakayama, K.; Barr, P. J.; Thomas, G. and Nagai, Y. 
(1992): Mammalian subtilisin-related proteinases in cleavage activation of the paramyxovirus fusion glycoprotein: superiority of furin/PACE to PC2 or PC1/PC3. J. Virol., 66: 6391-6397.

Hanson, R.P. and Brandly, C.A. (1955): Identification of vaccine strains of Newcastle disease virus. Science 122: $156-157$.

Herczeg, J.; Wehmann, E.; Bragg, R. R.; Travassos Dias, P. M.; Hadjiev, G.; Werner, O. and Lomniczi, B. (1999): Two novel groups (VIIb and VIII) responsible for recent Newcastle disease outbreaks in Southern Africa, one (VIIb) of which reached Southern Europe. Arch. Virol., 144: 2087-2099.

Kapczynski , D. R. and King, D. J. (2005): Protection of chickens against overt clinical disease and determination of viral shedding following vaccination with commercially available Newcastle disease virus vaccines upon challenge with highly virulent virus from the California 2002 exotic Newcastle disease outbreak. Vaccine 23:3424-3433.

Lomniczi, B.; Wehmann, E. ; Herczeg, J. ; BallagiPordany, A.; Kaleta, E.F.; Werner, O.; Meulemans, G.; Jorgensen, P.H.; Mante, A.P.; Gielkens, A.L.; Capua, I. and Damoser, J. (1998): Newcastle disease outbreaks in recent years inwestern Europewere caused by an old (VI) and a novel genotype (VII). Arch. Virol., 143: 49-64.

Mayo, M. A. (2002): A summary of taxonomic changes recently approved by ICTV. Arch. Virol. 147:1655-1656

Nagai, Y.; Klenk, H. D. and Rott, R. (1976): Proteolytic cleavage of the viral glycoproteins and its significance for the virulence of Newcastle disease virus. Virology 72: 494508 .

Ogasawara, T.; Gotoh, B.; Suzuki, H.; Asaka, J.; Shimokata, K.; Rott, R. and Nagai, Y. (1992): Expression of factor $\mathrm{X}$ and its significance for the determination of paramyxovirus tropism in the chick embryo. EMBO J., 11:467-472.

Panshin, A.; Shihmanter, E.; Weisman, T.; Orvell, C. and Lipkind, M. (2002): Antigenic heterogenicity among the field isolates of Newcastle disease virus (NDV) in relation to the vaccine strain. 1. Studies on viruses isolated from wild birds in Israel. Comp. Immunol. Microbiol. Infect.Dis., 25:95-108.

Reed, L. J. and Muench, H. (1938): A simple method for estimating fifty percent end points. Am.J.Hyg., 27:493-497. Reynolds, D. L. and Maraqa, A. D. (2000): Protective immunity against Newcastle disease: the role of antibodies specific to Newcastle disease virus polypeptides. Avian Dis., 44:138-44.

Rott, R. and Klenk, H-D. (1988): Molecular basis of infectivity and pathogenicity of Newcastle disease virus. In D.J. Alexander (ed.), Newcastle disease, Kluwer Academic Publishers, Boston. pp. 98-112.

Samson, A. C.; Levesley, I. and Russell, P. H. (1991): The 36K polypeptide synthesized in Newcastle disease virus-infected cells possesses properties predicted for the hypothesized 'V' protein. J. Gen. Virol., 72: 1709-1713.

Steward, M.; Samson, A. C.; Errington, W. and Emmerson, P. T. (1995): The Newcastle disease virus V protein binds zinc. Arch. Virol., 140:1321-1328.

Steward, M.; Vipond, I. B.; Millar, N. S. and Emmerson., P.T. (1993): RNA editing in Newcastle disease virus. J. Gen. Virol., 74: 2539-2547.

Toyoda, T.; Sakaguchi, T.; Hirota, H.; Gotoh, B.; Kuma, K.; Miyata, T. and Nagai, Y. (1989): Newcastle disease virus evolution. II. Lack of gene recombination in generating virulent and avirulent strains. Virology 169:273282.

Tsaia, H-J.; Chang, K-H.; Tsenga, C-H.; Frost, K.M.; Manvell, R. J.; Alexander D. J. (2004): Antigenic and genotypical characterization of Newcastle disease viruses isolated in Taiwan between 1969 and 1996. Vet. Microbiol., 104:19-30.

Villegas, P. and Purchase, G. (1989): Titration of biological suspension. In :Laboratory Manual for the Isolation and Identification of Avian Pathogens. 3rd ed. American Association of Avian Pathologists. H.G.Purchase, L.H.Arp., C.H.Domermuth, and J.E.Pearson eds. Kenall $\backslash$ Hunt publishing company, Iowa , USA. pp.186-190.

Yang, C-Y.; Chang, P-C.; Hwang, J-M. and Shieh, H.K. (1997): Nucleotide sequence and phylogenetic analysis of Newcastle disease virus isolates from recent outbreaks in Taiwan. Avian Dis., 41: 365-373.

Yang, C-Y.; Shieh, H.K.; Lin, Y-L. and Chang, P-C. (1999): Newcastle disease virus isolated from recent outbreaks in Taiwan phylogenetically related to viruses (genotype VII) from recent outbreaks in Western Europe. Avian Dis., 43: 125-130.

Yu, L.; Wang, Z.; Jiang, Y.; Chang, L. and Kwang, J. (2001): Characterization of newly emerging Newcastle disease virus isolates from the people's republic of China and Taiwan. J. Clin. Microbiol., 39: 3512-3519.

Yusoff, K.; Nesbit, M.; McCartney, H.; Meulemans, G.; Alexander, D. J.; Collins, M. S.; Emmerson, P. T. and Samson, A. C. (1989): Location of neutralizing epitopes on the fusion protein of Newcastle disease virus strain Beaudette C. J. Gen. Virol., 70:3105-310.

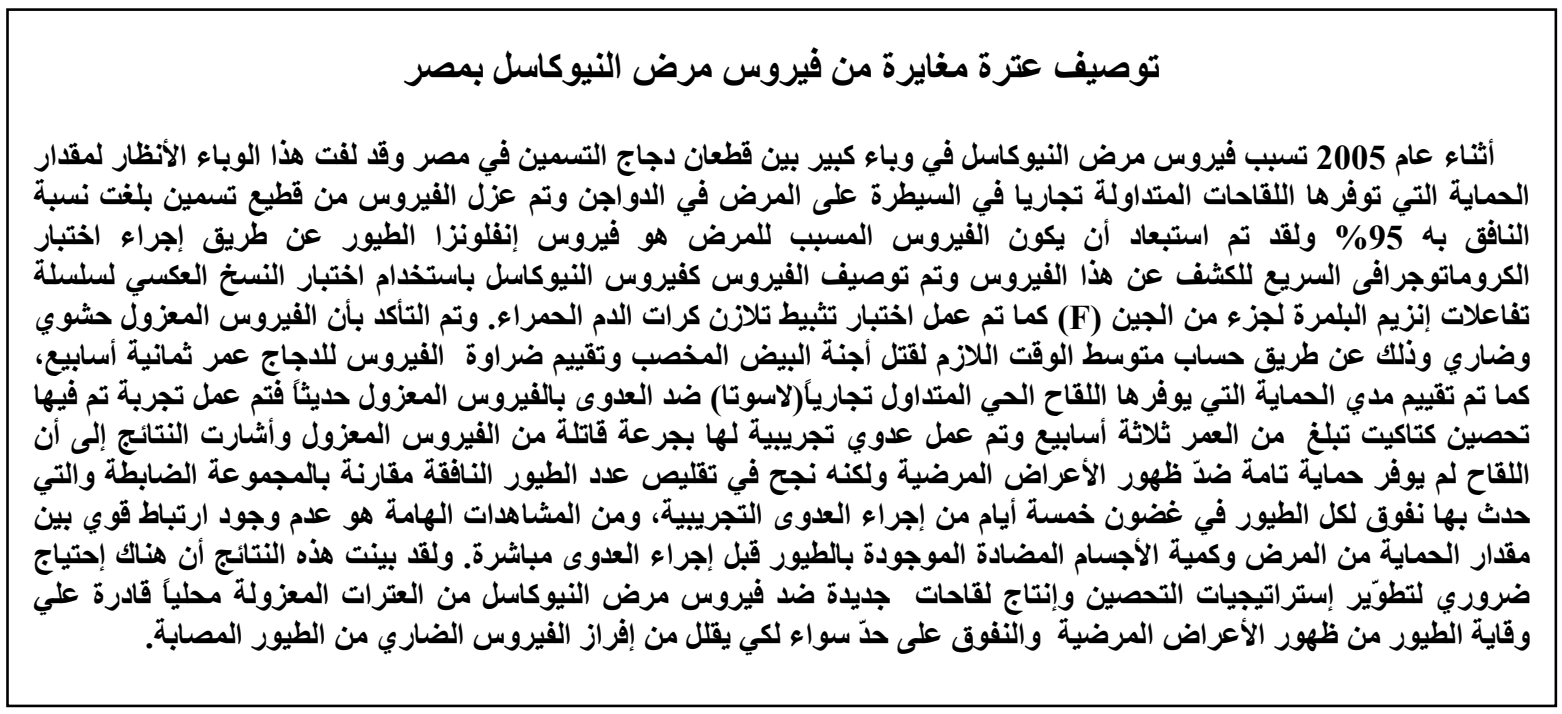

